\title{
Digital technology and creative arts career patterns in the UK creative economy
}

Article

Accepted Version

Comunian, R., Faggian, A. and Jewell, S. (2015) Digital technology and creative arts career patterns in the UK creative economy. Journal of Education and Work, 28 (4). pp. 346-368. ISSN 1363-9080 doi:

https://doi.org/10.1080/13639080.2014.997683 Available at https://centaur.reading.ac.uk/39942/

It is advisable to refer to the publisher's version if you intend to cite from the work. See Guidance on citing.

To link to this article DOI: http://dx.doi.org/10.1080/13639080.2014.997683

Publisher: Routledge

All outputs in CentAUR are protected by Intellectual Property Rights law, including copyright law. Copyright and IPR is retained by the creators or other copyright holders. Terms and conditions for use of this material are defined in the End User Agreement.

\section{www.reading.ac.uk/centaur}

\section{CentAUR}

Central Archive at the University of Reading 
Reading's research outputs online 


\title{
Digital technology and creative arts: embedded digital graduates and careers patterns in the UK creative industries
}

Dr Roberta Comunian, Department for Culture, Media and Creative Industries, King's College London, WC2R 2LS, UK. E-mail:

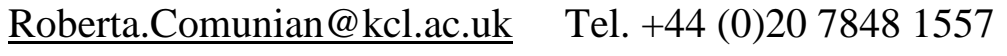

Dr Alessandra Faggian, Associate Professor, AED Economics Department

The Ohio State University, Columbus, Ohio USA E-mail: faggian.1@ osu.edu

Dr Sarah Jewell, Postdoctoral Research Fellow, School of Economics, University of Reading P O Box 218, Reading RG6 6AA, UK. E-mail: s.l.jewell@ reading.ac.uk

\begin{abstract}
The creative industries have attracted the attention of academics and policy makers for the complexity surrounding their development, supplychains and models of production. In particular, many have recognised the difficulty in capturing the role that digital technologies play within the creative industries. Digital technologies are embedded in the production and market structures of the creative industries and are also partially
\end{abstract}


distinct and discernible from it. This paper unfolds the role played by digital technologies focusing on a key aspect of its development: human capital. Using student micro-data collected by the Higher Education Statistical Agency (HESA) in the United Kingdom, we investigate the characteristics and location determinants of digital graduates. The paper deals specifically with understanding whether digital skills in the UK are equally embedded across the creative industries, or are concentrated in other sub-sectors. Furthermore, it explores the role that these graduates play in each sub-sector and their financial rewards. Findings suggest that digital technology graduates tend to concentrate in the software and gaming sub-sector of the creative industries but also are likely to be in embedded creative jobs outside of the creative industries. Although they are more likely to be in full-time employment than part-time or self-employment, they also suffer from a higher level of unemployment.

\section{Keywords:}

Digital technologies; embedded creative work; creative industries; human capital; creative graduates; 


\section{Introduction}

In this paper we ask what role digital human capital plays within and outside the creative industries. The paper argues that a better understanding of the human capital and skills behind 'digital technology' is key to map and capture the impact of the technological evolution on companies and on the overall economy. In previous work (Comunian, Faggian, and Li 2010) the contradiction between the key economic role of the creative class (Florida 2002a) and the low economic reward and career instability of the core creative workforce (Menger 1999) has been highlighted. However, there is very limited knowledge of the career patterns and job prospects of creative graduates in different subjects (see for an exception Faggian et al. 2012). This paper is concerned with exploring the career patterns of a sub-section of the creative graduates: graduates studying digital technology, and in particular the role they play across within and outside the creative industries. A recent report from NESTA (NESTA 2011) specifically considers the relationship between skills and two key digital sectors: video games and visual effect industries. It highlights the role played by higher education and underlies the important cross-over between artistic skills and STEM skills ${ }^{1}$. It is particularly important to understand the connections between 'digital technology' (from now on DT) graduates and creative industries but also the contribution that DT graduates in creative occupations make to the rest of the economy. This is even more relevant when looking at creative careers. There is a lack of comparative knowledge on what kind of creative careers are offered to creative and DT graduates, including their economic rewards and job patterns.

The paper argues that, in order to understand better the role and importance of digital technologies in the creative economy, we need first a better understanding of the role played by digital skills in relation to creative skills, both within and outside the creative sector. In order to do this, we use the concept of DT graduates as proxy for the embedding of digital skills in the broader creative economy. While some literature and policy reports have touched on the subject, this is a rather unexplored topic and very little comparative work, contrasting creative and digital skills and careers, exists.

The paper aims to address this specific gap, exploring the relationship between creative arts and digital technology skills in the creative economy in the UK. It considers the role of DT graduates in the creative labour market and offers a profile of their occupations, including the sector entered and salary. It also studies what factors influence the probability of a DT graduates finding a creative job (in or outside of the creative industries).

${ }^{1}$ STEM subjects are identified with the sciences, technology, engineering and maths. 
The paper is articulated in 4 sections. Section 1 introduces the literature and previous research in the field. Section 2 briefly describes the data and methodology used. Section 3 presents the results. Finally, Section 4 discusses the findings, concludes and presents further possible future research avenues.

\section{Research landscape: creative economy between creative and DT skills}

The paper explores issues related to a complex research and policy landscape, where different disciplines and policy frameworks overlap. Two key areas are briefly presented here in relation to the need of a better understanding of the connection between creative industries, creative work (in the broader economy) and DT skills. Firstly, we consider the relationship between DT industries and creative industries and jobs, arguing for the including of DT industries and skills in the broader creative economy. Secondly we briefly review the literature on working conditions of creative and media workers, highlighting the limited knowledge available on digital work.

The first aspect relates to the relationship between DT industries and occupations and the creative economy. The paper adopts this broader perspective and fully includes DT occupations and industries within the framework of the creative economy. While numerous authors have commented on the economic importance of the DT and software industries as part of the creative industries classification (Taylor 2006) there has been less discussion about DT occupations and their creative nature and contribution. We acknowledge that many authors take a more dynamic perspective, considering that while the DT sector might not be part of the core of the creative and cultural industries (Throsby 2001), it plays an ever growing role in the distribution and commercialisation of their content, within the creative supply chain and also in the creation of new markets for creative and cultural products (Potts et al. 2008). Furthermore, many argue that the whole creative class theory (Florida 2002b) is built on the dot.com boom and the explosion of technology driven creative companies in the early 2000s (Malanga 2004). The complex interconnection between DT, the creative industries and the broader economy has also strong policy implications. Potts and Cunningham (2011) questioned the narrow perspective of considering the 'creative industries' as a sector of the economy, instead they argue for an 'innovation model' of the creative industries, where creative industries are considered a part of the national innovation system, contributing to the generation of ideas and technology. However, it remains extremely difficult to measure and capture the interconnections between the creative industries and the larger economy (Faggian et al. 2012) and the analysis of the skills and labour force has been one of the most successful way to account for a creative economy. There is very little knowledge on the skill composition of the creative industries, although the literature tends to highlight the complex interplay between artistic and DT skills which need to be present within the sector (Healy 2002). The intrinsic use of DT is a key factor driving most of the sector of our contemporary economies, but it is said to play a fundamental role in the creative industries. Skillset (2010, 26) highlights that "across many sectors the Creative industries, skills in short supply from new entrants relate directly to new and digital technology". In the Creative Media industries, "the most common areas of training [needs] identified by employers are related to new and digital technology (one in four people). Within this particular framework the role played by higher education institutions and clustering of digital activities is also important (Sapsed and Mateos-Garcia 2011) and might have further links with dynamics of innovation (Hearn and Bridgstock 
2010). A recent report by NESTA - looking at the video games and visual effects sector - suggests that lots of the university courses in this subject area do not prepare students to be 'industry-ready'. They argue that "Universities too often appear to be focused on attracting students onto their course rather than pushing up the standards of those graduating" (NESTA 2011, 47). While this highlights the importance of gaining a better understanding of the labour market outcomes of graduates from these disciplines, it does not say much about how their job opportunities compare with other groups and in which sector their best job opportunities lie. It is crucial to understand whether the phenomenon mentioned in the NESTA report is specific to these subjects or is a widespread phenomenon that followed from the relentless expansion in higher education. What value does a 'digital' course provide and how does it compare with other disciplines? Are the much-advertised 'creative' occupations a good fit for graduates in these areas?

The second aspect of concern is related to creative careers. While it is widely acknowledged in the literature that careers in the creative field tend to be unstructured, often relying on part-time and temporary work as well as on low wages, our knowledge of how these characteristics differ across the creative industries and occupational sectors is very limited. There are many studies looking at the career difficulties faced by artists and creative workers, from unstable working patterns, to over-supply and lower economic rewards (Menger 1999, Comunian 2009). However, while these studies provide interesting insights on key issues faced by creative workers, they have the limit of clustering artistic and new digital professionals into a single group. Other authors have tried to look more closely at the workers in the digital and media industries (Christopherson 2002, Pratt 2000). However, most research in this field builds on qualitative analysis and case studies, which do not allow for comparative work across different creative disciplines.

The two areas of the literature summarised here are key in understanding what is still missing in our knowledge of the role of DT skills (within and beyond the creative industries). Investigating specific skills in the workforce is a very challenging area of research. As we want to specifically consider the role of skills and education, we use the Higher Education Statistical Agency (HESA) data. We will therefore use the category of DT graduates as proxy for digital skills. The HESA surveys are a very rich source of data and include individual information on all UK students and a large sample of all UK graduates. As such, it allows for a comparison of how different graduates from different disciplines, institutions and with different final grades fair when entering the labour market and how well their skills match what the market really requires.

Following these considerations, the paper aims to address three core research questions in relation to the role played by DT skills - represented by DT graduates - in the creative industries and its workforce.

- What role do DT graduates play in the creative labour market?

- What are the sectors entered and jobs undertaken by DT graduates?

- What factors influence the probability of a DT graduate entering a creative job (within and outside the creative industries) and what are the determinants of higher salaries in this sector? 


\section{Data, definitions and methodology}

\section{HESA Data}

Our analysis is based on data from the 'Destinations of Leavers from Higher Education' (DLHE) survey matched with their student record data, collected as part of the 'Students in Higher Education' survey, both collected by the UK Higher Education Statistical Agency (HESA). The DLHE survey, generally targeted towards British domiciled students, is a survey undertaken every year to collect information about graduates' employment activities six months after graduation. We concentrate our analysis on British domiciled students and, in particular, we focus on the cohort of students who graduated in 2005 (with employment data for 2006). As we are interested in employment patterns, these two years are particularly good as they refer to the pre-recession period.

The DLHE survey includes information on the graduate's employment, in particular: salary level, employer sector code (4-digit SIC code), job occupational code (4-digit SOC code), and location of employment (postcode). We obtain from the student record data information on personal characteristics (such as gender, age and ethnicity); subject of study (at the 4 digit Joint Academic Coding System (JACS) code); mode (full time vs. part time) and level of study (e.g. postgraduate, undergraduate); degree results and institution attended. We have a sample size of 313,800 (which is a response rate of $71 \%$ from the sample of all British graduates eligible for a DLHE return) who responded to the DLHE survey. Our sample size reduces slightly to 303,178 when we exclude those who provided an explicit refusal to the DLHE or were undertaking combined subjects (since it was not possible to classify these subjects). $24 \%$ of our sample are postgraduates, $66 \%$ of our sample our undergraduates and $10 \%$ other undergraduates below first degree level (such as higher national diplomas and certificates, foundation degrees)

While the figures we present for graduates within the creative industries are only a sub-sector of the overall creative workforce there are key supporting factors highlighting the relevance of this data (DaVanzo 1976): the creative industries workforce in the UK is young - 42\% in creative media are under 35 years old and $52 \%$ in the overall creative and cultural sector are under 40 years; the creative industries workforce in the UK is highly skilled $-57 \%$ in creative media and $54 \%$ in the creative and cultural sector have a degree or equivalent qualification (compared with only $35 \%$ of the general workforce).

\section{Definitions: subjects and creative industries and occupations}


In order to fully explore the role played by different skills in the creative job market, we group creative graduates in 2 main categories: digital technology graduates and creative arts \& design graduates, according to their main subject of study (identified by HESA through JACS codes). All the other graduates are included in the group 'other'.

Our subject definition is as follows:

1. Digital technology (DT), selected codes from $\mathrm{G}, \mathrm{H}, \mathrm{J}^{2}$;

2. Creative Arts and Design (CAD), all JACS codes beginning with W;

3. Other (all other JACS codes)

As in previous investigations (Comunian, Faggian, and Li 2010) we base the definition of creative occupations on the DCMS definition (1998; 2001). Using a creative occupations approach à la Cunningham et al (2004) we consider both creative careers within the creative industries but also creative jobs in other sectors. Our definition of a creative job is based on the initial DCMS definition based on 4-digit SIC codes (DCMS 2010). However, we supplement this definition with the inclusion of other creative workers based in sectors outside the creative industries as identified by a more recent DCMS document (DCMS, 2010). Moreover, we also took on board some of the criticisms to the DCMS definition provided by a recent report by NESTA (2008). Following NESTA (2008), we also classify a creative job as being:

- $\quad$ Specialised - in a creative occupation within the creative industries;

- $\quad$ Supportive - in a non-creative occupation within the creative industries;

- $\quad$ Embedded - in a creative occupation outside the creative industries.

When breaking down creative jobs into finer categories, we use the following groups: Advertising, Architecture and design engineers, Design, Designer fashion \& crafts, Film, TV, Radio and Photography, Music and Visual Performing Arts, Publishing, Software, computer games \& Electronic Publishing, Libraries, museums and cultural activities. Having sub-groups is important as creative jobs are very heterogeneous and there are substantial differences between sub-groups (McGranahan, Wojan, and Lambert 2011).

\section{Methodology}

\footnotetext{
${ }^{2}$ Codes include all computing sciences codes under G, all codes beginning with H6 (except H673 and codes beginning with H68 and H69) and all codes beginning with 552 and j93. See appendix 1 for more details about the JACS codes used.
} 
The paper employs a three-step methodology. Firstly we use descriptive statistics to explore the sample, how many graduates enter the labour market and how many specifically enter creative jobs or jobs in creative industries. We will consider also how many graduates from digital technology and how many from other subjects enter the digital technology sector.

Secondly, we present some descriptive statistics focused specifically on the differences across creative sub-sectors. We explore what sub-sectors of the creative and non-creative economy employs more digital technology graduates and which sector offers them better opportunities to undertake a graduate level job and what type of jobs (Specialist; Support; Embedded) they enter in each sector. Within this analysis, we also consider the reasons that these graduates provided for taking a job in the creative sector.

Lastly we use a logit model to examine the factors influencing the probability of digital technology graduates entering a creative occupation.

Here we only use first degree students so we can examine the effect of degree class as others have done (Faggian et al. 2012). We also consider the economic rewards given, for undergraduate students, and what weight it might have on the choice of entering the sector. We make use of the salary variable obtained in the DLHE survey (with the full time equivalent asked for those working less than full time), which is reported by 67,720 employed first degree individuals and we exclude those who claim to earn less than the national minimum wage ${ }^{3}$ and those who report values of $£ 100,000$ above as a result of the possibility of an extra 0 having been accidently added, leaving 59,406 salary observations.

\section{Results}

\section{Descriptive statistics}

The first part of this section provides some basic statistical information on our sample with a specific focus on creative graduates and their labour market outcomes. As shown in Table 1 the DT (7\%) and CAD students (9\%) comprise about 16\% of our sample student population. Although these might seem small percentages, there has been a growing interest in these subjects and many institutions have seen a substantial increase in the number of students taking these courses in the last decade (Heartfield 2005). The Higher Education Statistical Agency (2009) highlights the steady growth of creative subject areas. Between 2003/2004 and 2007/2008 Architecture, Building and Planning has shown the

\footnotetext{
${ }^{3}$ If we assume that full time individual’s work a minimum of 30 hours for 52 weeks and using the minimum wage as of January 2006 which was $£ 4.25$ this equates to $£ 6630$ which we rounded down to $£ 6500$.
} 
highest growth of $34.2 \%$, Creative arts and design have shown a $14.2 \%$ increase, while Mass Communication and documentation $7.3 \%$. The overall growth across all subjects has been $4.8 \%$.

\section{INCLUDE TABLE 1 HERE}

Past research has shown that creative graduates in general tend to have worse labour market conditions associated with lower paid and part-time jobs (McGranahan, Wojan, and Lambert 2011). DT students are similar to CAD graduates (see Table 1) in many respects but there are some notable differences. On one side, DT graduates have the highest unemployment rate among all graduates $(9.3 \%$ compared to $4.55 \%$ for graduates from other subjects), even compared with CAD students $(8.4 \%)$. On the other, however, DT students are less likely to be part time (6.78) or voluntary/unpaid jobs $(0.52 \%)$ compared to other graduates $(7.40 \%$ and $0.71 \%)$, and especially compared to other CAD graduates (12\% and $1.1 \%)$. The higher unemployment rate can be explained in different ways. It could be linked to an oversupply of students in these subjects - which would go with how popular these courses were in the last decade together with the aftermath of the dot.com bubble bursts - but also to the graduates not having the appropriate skills required by the market (Haukka 2011). There is a general need for the universities to look at what kind of graduates are required from the market in an effort to produce the right type of graduate with the desired skills to meet the demand of employers. This is certainly true in the creative sector ${ }^{4}$ but also elsewhere. Another interesting observation - which could be also linked to the higher level of unemployment of DT graduates - is the level of self-employment/freelancing: only $2.71 \%$ of DT graduates are working freelance or being self-employed compared with $8.53 \%$ of CAD graduates choosing this option. While our previous knowledge of creative graduates' career patterns remains relevant, it is clear that DT students' experiences differ from CAD graduates. It is, therefore, important to explore these differences further to understand the underlying reasons for this.

Table 2 provides a breakdown of the sector sizes (as well as those within the creative sector) of those employing graduates (based on the graduates in our sample) and whether they are graduate level jobs, as defined Elias and Purcell (Elias and Purcell 2004), along with a breakdown of which subjects they employ. The creative sector employs $13 \%$ of new graduates in the labour market and constitutes $16 \%$ of graduate level jobs for new entrants, with the best provider of jobs being the health and social welfare and education sectors which together employ around $42 \%$ of employed graduates and represent $51 \%$ of graduate jobs. Within the creative sector the biggest provider of jobs is the software, computer games and electronic publishing sector that employed 2.8\% of all graduates entering the labour market in 2006 and $3.7 \%$ of graduate level jobs..

\footnotetext{
${ }^{4}$ Although this is a broader question, which the present paper cannot answer, there has been research highlighting the need for universities to link more with the creative sector to respond to the needs of employers see Heartfield (2005)
} 
It is noticeable - and relatively good news - that a high proportion of jobs taken by graduates are graduate level jobs and this is particular true in advertising, architecture and design engineering, and software, computer games and publishing. It is also interesting to look at how different degrees are linked to the 'creative sector'. Overall 58\% of graduates employed in the creative sector are from degrees that are neither creative nor linked to DT (in particular 30\% are from humanities (Comunian, Faggian, and Jewell 2014). However, there are clear differences between the creative sub-sectors. In particular, DT graduates make up $67 \%$ of graduates employed in the software sector although their skills seem to be of some value also in the design sector (9.2\%) and in the 'film, tv, radio and photography' sector (10.2\%). As expected, the design and music sectors mainly employ CAD graduates ( $70 \%$ and $50 \%$ respectively). The rest of the creative sub-sectors employ the majority of their graduates from 'other' degrees (for example 57\% in the libraries, museums and art gallery sector are humanities students).

What is worth noticing is that in some sub-sectors of the creative economy the skills sought after by employers are very 'specific' and require a specific degree, while in others the more 'general' (and more transferrable) skills are very valuable and - in some cases - more valuable than specific ones, making the market more open to competition from graduates in other disciplines (and institutions). This may have some bearing on the differing labour market outcomes experienced by graduates from different degrees. Furthermore there has also been a broader policy argument for innovation and new technologies to be embedded across different sectors of the creative and cultural industries (NESTA 2010), which our data seem to contradict. However, it is also true that in a sector like the creative industries - characterised by small and medium size enterprises - collaboration across sectors might take place and be more advantageous than embedding certain professionals across diverse sectors.

\section{INCLUDE TABLE 2 HERE}

\section{Creative labour market and DT graduates}

After understanding the main characteristics and work patterns of DT graduates, we now turn to their interconnection with the creative sector. Table 3 presents the sector distribution of graduate creative jobs, with a further breakdown of the type of creative degree studied. DT (36.35\%) and CAD graduates $(35.5 \%)$ are more likely to enter the creative sector than other sectors, as well as being more likely to enter the creative sector compared to other graduates (9.10\%). Even so, only a third of DT and CAD graduates end up in the creative sector, with almost $20 \%$ of DT students entering the science, engineering and technology industry. It is worth also noticing the importance of Education for CAD graduates $20 \%$ (more than double of the digital technology students 9\%). Within the graduates entering creative jobs, DT graduates are the most concentrated- with $77 \%$ going into the software, electronic games and publishing sector. This seems to point to a very good-fit between the topic studied at university and the occupation entered and it is linked mainly to the high level of specialisation of these graduates, although it should 
also be mentioned that digital work - for its nature and size - often tends to be outsourced rather than incorporated in the functions of other sectors.

\section{INCLUDE TABLE 3A HERE}

In terms of the 'type' of creative job (i.e. Specialist, support or embedded), graduates from different subjects not only enter different creative sub-sectors but also play different roles. For example 53\% of DT students are embedded, with 33\% in specialist roles, whilst only $14 \%$ are in support roles.

This seems to highlight the fact that other sectors are able to embed DT graduates, offering them creative occupations even outside creative industries (see table $3 \mathrm{~b}$ ). It also suggests recognition of the value and skills of DT graduates in the broader economy (e.g. a web designer in a manufacturing industry). The fact that DT graduates are less likely to be in specialised positions seems to highlight a difficulty in entering core creative occupations within creative industries, which is comparable to the position occupied by the general 'Others' group. Non-creative graduates, with the exception of those from humanities (Comunian et al. 2014), tend to play a bigger support role than creative graduates and are less likely to be in specialist roles.

When asked about the reasons for taking their job, $40.5 \%$ of DT graduates stated that the "job fitted into their career plan". This compared favourably with CAD graduates (37.7\%) but negatively with 'other' graduates (47.8\%). However, once restricting the sample only to those employed in the creative sector, DT graduates were the most likely to report a good fit $(50.7 \%$ compared to $48.8 \%$ for creative graduates and $46.2 \%$ for other graduates). This seems to suggest that although DT students may find it harder to enter the labour market (see higher level of unemployment in Table 1), those who find a job are more likely to see a fit with their career plan (possibly preferring to be unemployed than finding a non-suitable job) especially in the case of creative jobs. Across all students it is noticeable that the proportion reporting that they took the job "To gain experience in order to get the type of job I really want" (26.2\% versus $18.4 \%)$ or "To broaden my experience/to develop general skills" (34.2\% versus $28 \%)$ is much higher among creative jobs than non-creative jobs - suggesting that jobs in the creative sector are more likely to be a stepping stone to a career graduates really want.

Graduates were also asked about the self-reported importance of the qualification and subject studied in their work environment. While both DT and CAD graduates are more likely to report the qualification was an 'advantage' (23\% vs. 19\% of the rest of graduates), they are less likely than graduates from 'other' degrees to report that the qualification was a formal requirement (around $40 \%$ for the DT graduates, $31 \%$ for CAD graduates and around $46 \%$ for other graduates). While this is maybe to be expected for creative arts jobs, it is somewhat more surprising for DT 
graduates. However, this could be due mainly to 'bad' job-qualification matches. This hypothesis seems to be confirmed by the fact that, once restricting the sample to creative jobs, DT graduates are the most likely to report that the qualification was a formal requirement or expected (around 54\% for DT graduates compared to $38 \%$ for CAD graduates and $43 \%$ for other graduates).

Another interesting finding is that DT graduates are more likely to report that both their degree subject and level are important for their job. This suggests that in their occupations they make use of both the more 'specific' human capital (degree subject) and the more 'general' (transferrable) skills developed at university.

When we look more closely at the 'embedded' DT graduates, we find that less than 50\% are employed in the Science, Technology \&

Engineering and the rest a spread across the other sectors of the economy with a strong presence in the Financial, Property \& Business (24.23\%) and also the Public administration sector (7.20\%). Compare with CAD graduates, DT graduates are more embedded in the public administration sector (7.20\% vs. $4.38 \%)$ and less present in the education sector $(6.39 \%$ vs. $9.70 \%)$. This seems to suggest that a broad range of sectors is able to embed DT graduates, as they enter creative occupations within a broad range on non-creative industries (as described above). It seems important to notice that DT graduates are therefore able to contribute to the broader. However, on the contrary, the fact that DT graduates are less likely to be in specialised positions (with a creative job within the creative industries) seems to suggest that DT find it difficult to gain core creative occupations within creative industries.

\section{INCLUDE TABLE 3B HERE}

Entry salary levels of DT graduates are much higher than other creative graduates and in line with the general graduate population (Table 4). DT graduates earn significantly more by being in a creative job, which is the opposite of other graduates who earn significantly less, with no significant difference for CAD students ${ }^{5}$.

\section{INCLUDE TABLE 4 HERE}

${ }^{5}$ T-values from significance tests of differences between non-creative and creative job salaries by subject group were -8.1994, -0.2061 and 15.427 for DT, CAD and other graduates respectively. 
Table 5 shows that there are big differences in salary outcomes across the creative sector. The software industry offers higher earnings - on average. In this respect, DT graduates are better placed to receive higher economic rewards for their skills, than creative graduates in general. Across the creative sector, embedded creative graduates earn more than graduates in specialised and supportive roles.

\section{INCLUDE TABLE 5 HERE}

\section{DT graduates in the creative economy: jobs and salary profile}

After analysing the overall dynamics and job patterns of DT graduates, we model the likelihood of getting a creative job - for all students and digital technology graduates separately - using a logit model (table 6).

From the results of the logit model, it clearly emerges that DT and CAD graduates are more likely to be in a creative job than other graduates.

\section{INCLUDE TABLE 6 HERE}

While the type of HEI attended (i.e. Russell group, old university, new university or college) does not have an effect on the likelihood of entering a creative sector, it is important for DT graduates. DT graduates for the self-reported most prestigious HEIs (the so-called Russell group) are almost $34 \%$ more likely to find a job in the creative economy. This means that the best graduates prefer to enter in a creative occupation probably feeling it is the best fit for them. Creative occupations also seem to attract graduates who are younger and did better in their degree (ending up with the top grade, i.e. a 'first').

Although we reported the average entry salaries by subject group in Table 4, we did not comment on the possible factors influencing these salaries. Table 7 reports the results of salary regressions where different salary determinants have been included. We report the results separately for all graduates (columns 1 and 2) and for the ones employed in creative jobs (columns 3 and 4). Models 1 and 3 do not include sector fixed 
effects, while models 2 and 4 include them. Although not reported in the table control variables for gender, age, ethnicity, disability, job attributes (whether part time, freelance/self-employed) and region of employment were also included.

\section{INCLUDE TABLE 7 HERE}

As reported in Table 7 there is a premium from having a degree from a Russell group university (about $7 \%$ in general, and between 3 and $4 \%$ in the creative sector) and graduating with a good grade (a 'first' is associated with around $5 \%$ higher entry salary).

DT graduates employed within the creative sector earn about $10 \%$ more than the rest of the graduates, although this premium decreases to about $3 \%$ once we control for the different creative sub-sectors. Interesting findings come out in model 4 when considering these sub-sectors. Not all the creative sub-sectors are equally advantageous. The software industry pays, on average, the highest entry salaries (about $10 \%$ more than other jobs) followed by architecture. The library and film sectors are associated with salary disadvantages of about $16 \%$ and $10 \%$ respectively.

Embedded jobs on average pay more than specialist or support jobs, implying that non-creative sectors are willing to pay for creative skills, more than creative sectors (i.e. specialist jobs). With DT students most likely to be in embedded jobs (see Table 3). These findings suggest that DT students are particularly valued within the creative sector but even more so in non-creative sectors, whilst creative graduates earn the least in both the creative and non-creative sectors.

Although not reported in Table 7, some results on the other control variables are worth mentioning. First, females earn less than males. This is not surprising and it is consistent with previous studies (Comunian et al. 2010). What is surprising, however, is that this effect is even stronger within creative jobs. While salaries increase with age - as predicted by human capital models (Becker 1993) - this effect is weaker for creative.

\section{Discussion and Conclusions}

The paper has tried to gather a better understanding of the role played by DT human capital and skills in and beyond the creative industries, with particular focus on the differences between DT graduates and CAD graduates. 
The paper has explored the role played by DT graduates in the creative labour market. Our findings highlight that the creative industries employ a variety of graduates but CAD and DT graduates are the most likely student group to enter a creative job. Different sub sectors of the creative economy employ different types of graduates - with DT graduates being a big constituent of the software sector but also being employed in other creative jobs outside of the creative industries.

In reference to the sectors and jobs entered by DT graduates, the paper highlights the degree of specialisation of these students but also the potential lack of digital skills (measured here as number of DT graduates) across the creative industries (if we exclude the software sector). DT graduates are more likely to be embedded in non-creative industries than other subjects, with CAD graduates the most likely to be in specialist roles (creative occupations in creative industries). While previous research has shown the poor monetary rewards and unstable employment patterns of creative graduates, graduates in DT show a different profile. DT graduates earn more than CAD graduates, and gain more by being in a creative job than others. Within creative jobs, DT graduates earn the most with CAD graduates earning the least. The software industry is the highest paid industry, on average, with architecture and advertising paying more than non-creative sectors. DT students are more likely to enter the software industry. While their earnings are better, surprisingly they suffer from higher level of unemployment than CAD graduates highlighting a potential difficulty in entering the job market, possibly linked to a concentration of jobs in specific sectors (and specific locations). More research needs to be done to fully understand why but the motivations - including a low recognition of formal qualification by employs and shortcoming in meeting the industry needs - presented by Haukka in relation to the Australian case study might be relevant also for the UK (2010). They play a particularly important role in the creative job markets as DT (36.4\%) - followed by CAD (36\%) - are more likely to enter the creative sector than other sectors.

DT skills can therefore be seen as being more broadly relevant to the wider economy than creative arts skills. We have also highlighted how DT graduates follow specific working paths within the creative economy. Different sub sectors of the creative economy employ different types of graduates and a clear pattern emerges for DT graduates being a big constituent of the software sector (76.77\%) with a very marginal presence across other sectors (such as design and film and tv). In fact, while numerous policy documents suggest the important of the digital dimension to the overall creative industries (DCMS and BIS 2009, NESTA 2010), we found little evidence of these skills being employed across other sectors - apart from design and film and television (OECD 2008b). This might be due to the limited size and resources available to arts and cultural industries (in sectors such as publishing or performing arts) and the patterns of collaborative work - which cannot be captured by our data might facilitate the exchange / embedding of these skills on a temporary basis (Sturgeon 2003). However, DT students clearly see the creative economy as a key sector for their employment and are more likely (when employed in a creative job) than CAD students (but not other subjects) to state the "job fitted into their career plan".

Finally the papers has also considers what factors influence the probability of a DT graduates to take a creative job or working in the creative industries and what factors influence higher economic rewards in this sector. Our salary model results suggest that DT graduates earn more than CAD graduates, and earn more by being in a creative job, which is where they naturally find their best fit. Furthermore, they are more likely to 
be in embedded jobs - which were also emerging as being more lucrative. The results also suggest that - in a world where we are witnessing a 'massification' of higher education - having a degree is a necessary but not sufficient condition to find a good graduate entry-job in the labour market. In particular, for DT graduates, the HEI attended matters. Being from a (self-reported) more prestigious HEI (such as the ones belonging to the Russell group) increases the chance of DT graduates landing a higher paid job as does having graduated with a top mark (i.e. a 'first'). In other words, 'quality' matters.

The paper and discussion has been limited to the UK policy framework. While it is clear that this agenda has acquired recently also a strong EU and international dimension (EC 2001, OECD 2008a), it was impossible to make broader considerations on these wider contexts, due to the limitations of our data, which refer only to UK graduates. However, the findings from the paper are an initial framework for discussion which could benefit also the international policy arena.

The paper has strong policy implications. It seems to suggest that contrary to common arguments about the role played by technology and innovation in the creative sector (as measured by the employment of DT graduates) in the creative industries remain narrowly concentrate in the software sector. Initiatives such as the 'The Digital R\&D Fund for the Arts ${ }^{6}$ ' (with funding from NESTA, AHRC and Arts Council of England) and other policies bodies (including the new Digital Economy programme launched by Research Councils UK) are focusing on bridging this gap but more needs to be done for the creative industries to benefit from the advances of DT. Although this was not the focus of the paper, similar arguments could be made about the limited presence of CAD graduates in the software and gaming sector, contrary to NESTA (2010) which sees the sector as benefitting from both digital and creative skills. The policy implications of the paper also extend to higher education policy. It can be argued that while public policy has tried to promote a broader understanding of the creative industries and their ecology, especially in relation to the role played by technology, graduates skills still are very much structured in silos. The fact that DT graduates have greater career opportunities and salaries that other CAD graduate could be a result also of the silos structure of higher education provision. New curricula innovation might provide a solution to a better integration of graduates and skills across the economy (Cunningham and Bridgstock 2012).

The paper has been a first investigation in the role of human capital in bridging our understanding of the way DT are embedded and core to the creative industries. There is very little literature and data in this area of research and the paper has only highlighted some key issues and dimensions of this debate but further research needs to be undertaken. We need a better understanding of how DT skills are used in embedded ways across a variety of sectors. Skillset (Skillset 2010, 27) reports that "a major gap in skills (and knowledge) evident across the Creative Industries is working with and exploiting digital technological advances (including specific software applications)", we argue that a better understanding of how these skills enter the creative economy is also important.

6 "The Fund, a partnership between NESTA, the Arts Council England and the Arts and Humanities Research Council (AHRC), is unique in encouraging collaboration between the arts, digital technology providers and the research community in order to undertake experiments from which the wider arts sector can learn" (from http://www.artsdigitalrnd.org.uk/ accessed $28^{\text {th }}$ October 2012) 


\section{Bibliography}

Becker, G S. 1993. Human Capital: A Theoretical and Empirical Analysis, with Special Reference to Education Chicago: University of Chicago Press.

Christopherson, Susan. 2002. "Project work in context: regulatory change and the new geography of media." Environment \& Planning A no. 34:20032015.

Comunian, R, A. Faggian, and Qian Che Li. 2010. "Unrewarded careers in the creative class: The strange case of Bohemian graduates." Papers in Regional Science no. 89 (2):389 - 410

Comunian, R., A Faggian, and S Jewell. 2014. "Embedding Arts and Humanities in the Creative Economy: the role of graduates in UK." Environment and Planning $C$ no. forthcoming.

Comunian, Roberta. 2009. "Questioning creative work as driver of economic development: the case of Newcastle-Gateshead." Creative Industries Journal no. 2 (57-71).

Comunian, Roberta, Alessandra Faggian, and Sarah Jewell. 2011. "Winning and losing in the creative industries: an analysis of creative graduates' career opportunities across creative disciplines." Cultural Trends no. 20 (3/4):291-308.

Cunningham, S, T Cutler, G Hearn, M Ryan, and M Keane. 2004. "An innovation agenda for the Creative Industries: Where is the R\&D?" Media International Australia: incorporating Culture \& Policy no. 112:174-185.

Cunningham, Stuart, and Ruth Bridgstock. 2012. "Say goodbye to the fries : graduate careers in media, cultural and communication studies." Media International Australia Incorporating Culture and Policy no. 145.

DaVanzo, Julie. 1976. "Differences between Return and Non-return Migration: An Econometric Analysis." International Migration Review no. 10 (1):13-27.

DCMS. 2010. Creative Industries Economic Estimates. London: DCMS.

DCMS, and BIS. 2009. Digital Britain: Final Report. London: Department for Culture, Media, Sport and Department for Business, Innovation and Skills.

EC. 2001. "Exploitation and Development of the job potential in the Cultural Sector in the age of Digitalisation." DG Employment and Social Affairs.

Elias, Peter, and Kate Purcell. 2004. "Is Mass Higher Education Working? Evidence from the Labour Market Experiences of Recent Graduates." National Institute Economic Review no. 190 (1):60-74. doi: 10.1177/002795010419000107.

Faggian, Alessandra, Roberta Comunian, Sarah Jewell, and Ursula Kelly. 2012. "Bohemian Graduates in the UK: Disciplines and Location Determinants of Creative Careers." Regional Studies:1-18. doi: 10.1080/00343404.2012.665990.

Florida, R. 2002a. "The Economic Geography of Talent." Annals of the Association of American Geographers no. 92 (4):743 - 755.

Florida, R. 2002b. The Rise of the Creative Class, (and how it's transforming work, leisure. community \& everyday life). New York: Basic Books.

Haukka, Sandra 2010. From education to work in Australia's creative digital industries: comparing the opinions and practices of employers and aspiring creatives. Brisbane: Queensland Institute of Technology.

Healy, Kieran. 2002. "Survey article: Digital Technology and Cultural Goods." The Journal of Political Philosophy no. 10 (4):478 - 500. 
Hearn, Gregory, and Ruth Bridgstock, eds. 2010. Education for the creative economy : innovation, transdisciplinarity, and networks. Edited by Daniel Araya and Michael A. Peters, Education in the Creative Economy : Knowledge and Learning in the Age of Innovation. New York: Peter Lang. Heartfield, James. 2005. The Creativity Gap. London: Blueprint, ETP Ltd.

Higher Education Statistical Agency (HESA). 2009. Press release 141- Science and Medicine studies see five year growth. Cheltenham: HESA.

Malanga, S. 2004. "The Curse of Creative Class." City Journal, Winter 2004.

McGranahan, David A., Timothy R. Wojan, and Dayton M. Lambert. 2011. "The rural growth trifecta: outdoor amenities, creative class and entrepreneurial context." Journal of Economic Geography no. 11 (3):529-557. doi: 10.1093/jeg/lbq007.

Menger, P. M. 1999. "Artistic Labor Markets and Careers." Annual Review of Sociology no. 25:541-574.

NESTA. 2008. Beyond the creative industries: mapping the creative economy in the United Kingdom. London: NESTA

NESTA. 2010. Culture of Innovation. London: NESTA.

NESTA. 2011. Next Gen. Transforming the UK into the world's leading talent hub for the video games and visual effects industries. A Review by Ian Livingstone and Alex Hope. London: NESTA.

OECD. 2008a. "Digital Content in Transition." In OECD Information Technology Outlook 2008. OECD Publishing.

OECD. 2008b. Remaking the Movies: Digital Content and the Evolution of the Film and Video Industries: OECD Publishing.

Potts, Jason, John Hartley, John Banks, Jean Burgess, Rachel Cobcroft, Stuart Cunningham, and Lucy Montgomery. 2008. "Consumer Co-creation and Situated Creativity." Industry and Innovation no. 15 (5):459-474. doi: 10.1080/13662710802373783.

Pratt, Andy C. 2000. "New media, the new economy and new spaces." Geoforum no. 31 (4):425-436.

Sapsed, Jonathan, and Juan Mateos-Garcia. 2011. The role of universities in enhancing creative clustering. In Brighton Fuse: Enhancing the Creative, Digital and Information Technology Industries (CDIT) in Brighton: CENTRIM, University of Brighton.

Skillset. 2010. Strategic Skills Assessment for the Creative Industries. London: Skillset.

Sturgeon, Timothy J. 2003. "What really goes on in Silicon Valley?Spatial clustering and dispersal in modular production networks." Journal of Economic Geography no. 3:199 - 225.

Taylor, C. 2006. "Beyond Advocacy: Developing an Evidence Base for Regional Creative Industry Strategies." Cultural Trends no. 15 (1):3 -18.

Throsby, David. 2001. Economics and Culture. New York, Cambridge, Melbourne: Cambridge University Press.

Appendix 1

\begin{tabular}{|l|l|}
\hline $\begin{array}{l}\text { Creative Sub- } \\
\text { disciplines }\end{array}$ & JACS codes \\
\hline $\begin{array}{l}\text { Digital } \\
\text { Technology }\end{array}$ & $\begin{array}{l}\text { G4 Computer Science (includes sub-disciplines such as Computer Architectures \& Operating Systems; Networks and } \\
\text { Communications; Human-computer Interaction; Multi-media Computing Science, G5 Information science; G6 Software }\end{array}$ \\
\hline
\end{tabular}




\begin{tabular}{|l|l|}
\hline & $\begin{array}{l}\text { Engineering (includes sub-disciplines such as Software Design and Programming); G7 Artificial Intelligence; G92 Other } \\
\text { Computer Science; H6 Electronic and Electrical Engineering (with the exception of H673 Bioengineering, H68 } \\
\text { Optoelectronic Engineering and H69 Electronic and Electrical Engineering Not Classified Elsewhere); J52 Printing (includes } \\
\text { sub-disciplines like Offset Lithography, Photo-Lithography, Reprographic Techniques, Screen Process Printing); J93 } \\
\text { Technology (includes: Audio Technology and Music Recording). }\end{array}$ \\
\hline $\begin{array}{l}\text { Creative Arts } \\
\text { and Design }\end{array}$ & $\begin{array}{l}\text { W1 Fine Art; W2 Design Studies; W3 Music; W4 Drama; W5 Dance; W6 Cinematics and Photography ;W7 Crafts; W8 } \\
\text { Imaginative Writing; W9 Others in Creative Arts and Design }\end{array}$ \\
\hline Other & All other JACS codes \\
\hline
\end{tabular}


Table 1: Destination by Subject Group

\begin{tabular}{|c|c|c|c|}
\hline & \multicolumn{2}{|c|}{$\begin{array}{c}\text { Creative } \\
\text { Graduates }\end{array}$} & \multirow[t]{2}{*}{ Other } \\
\hline & DT & CAD & \\
\hline No of Obs. & 21,435 & 27,713 & 254,030 \\
\hline$\%$ & 7.07 & 9.14 & 83.79 \\
\hline \multicolumn{4}{|l|}{ Destination (\%) } \\
\hline Labour Market Entrants & 73.07 & 73.28 & 77.68 \\
\hline Full-time paid work & 54.82 & 43.72 & 57.52 \\
\hline Freelance/self-employed & 2.71 & 8.53 & 1.48 \\
\hline Part-time paid work & 6.78 & 12.01 & 7.4 \\
\hline Voluntary/Unpaid work & 0.52 & 1.09 & 0.71 \\
\hline Work and Study & 8.24 & 7.92 & 10.57 \\
\hline $\begin{array}{l}\text { Non-Labour Market } \\
\text { Entrants }\end{array}$ & 26.93 & 26.72 & 22.32 \\
\hline Further Study only & 13.02 & 12.43 & 12.67 \\
\hline Assumed to be unemployed & 9.26 & 8.36 & 4.55 \\
\hline $\begin{array}{l}\text { Not available for } \\
\text { employment }\end{array}$ & 3.41 & 4.09 & 4.13 \\
\hline Other & 1.24 & 1.83 & 0.96 \\
\hline
\end{tabular}


Table 2: Sector Size and Graduate Level Jobs

\begin{tabular}{|c|c|c|c|c|c|c|c|c|}
\hline & \multirow{3}{*}{$\begin{array}{r}\text { No of } \\
\text { Jobs }\end{array}$} & \multirow{3}{*}{$\begin{array}{r}\% \text { of } \\
\text { all jobs }\end{array}$} & \multirow{3}{*}{$\begin{array}{r}\% \text { of } \\
\text { graduate } \\
\text { level } \\
\text { jobs }\end{array}$} & \multirow{3}{*}{$\begin{array}{r}\% \text { Jobs } \\
\text { in Sector } \\
\text { Graduate }\end{array}$} & \multicolumn{4}{|c|}{ Subject distribution Employed by Sector } \\
\hline & & & & & \multicolumn{4}{|c|}{ Creative Graduates } \\
\hline & & & & & DT & CAD & Other & Total \\
\hline Creative sector & 30,850 & 13.23 & 15.96 & 87.32 & 18.43 & 23.36 & 58.21 & 100 \\
\hline Advertising & 4,720 & 2.02 & 2.66 & 94.93 & 3.56 & 7.99 & 88.45 & 100 \\
\hline Architecture and design & 4,380 & 1.88 & 2.48 & 95.43 & 4.09 & 4.00 & 91.92 & 100 \\
\hline Design, designer fashion \& Crafts & 4,557 & 1.95 & 2.49 & 91.97 & 9.26 & 70.48 & 20.25 & 100 \\
\hline Film, TV, Radio and Photography & 2,745 & 1.18 & 1.19 & 73.28 & 10.20 & 35.59 & 54.21 & 100 \\
\hline Music and Performing Arts & 3,507 & 1.50 & 1.70 & 81.75 & 3.82 & 49.87 & 46.31 & 100 \\
\hline Publishing & 2,518 & 1.08 & 1.18 & 78.98 & 3.53 & 12.11 & 84.35 & 100 \\
\hline $\begin{array}{l}\text { Software, computer games \& } \\
\text { Electronic Publishing }\end{array}$ & 6,519 & 2.80 & 3.67 & 94.94 & 66.85 & 2.53 & 30.62 & 100 \\
\hline Libraries, museums \& art galleries & 1,858 & 0.80 & 0.58 & 53.01 & 2.53 & 12.65 & 84.82 & 100 \\
\hline Science, Technology \& Engineering & 22,230 & 9.53 & 10.03 & 76.27 & 13.65 & 3.38 & 82.97 & 100 \\
\hline Health \& Social Welfare & 51,775 & 22.20 & 27.31 & 89.06 & 0.94 & 1.61 & 97.44 & 100 \\
\hline Education & 45,981 & 19.72 & 23.83 & 87.48 & 3.05 & 8.99 & 87.96 & 100 \\
\hline Financial, Property \& Business & 33,221 & 14.24 & 12.72 & 64.68 & 5.58 & 4.93 & 89.49 & 100 \\
\hline Public Administration & 12,443 & 5.34 & 3.92 & 53.28 & 5.29 & 3.73 & 90.98 & 100 \\
\hline Other & 36,718 & 15.74 & 6.23 & 28.63 & 6.86 & 14.35 & 78.79 & 100 \\
\hline Total & 233,218 & 100 & 100 & 72.41 & 6.71 & 8.70 & 84.59 & 100 \\
\hline
\end{tabular}


Table 3a: Sector Distribution and Creative Job Type by Subject studied

\begin{tabular}{lrrr}
\hline & DT & CAD & Other \\
\hline Sector (\%) & & & \\
Creative Sector & 36.35 & 35.50 & 9.10 \\
Science, Technology \& Engineering & 19.40 & 3.70 & 9.35 \\
Health \& Social Welfare & 3.13 & 4.11 & 25.57 \\
Education & 8.97 & 20.37 & 20.50 \\
\hline Financial, Property \& Business & 11.85 & 8.07 & 15.07 \\
Public Administration & 4.21 & 2.29 & 5.74 \\
Other & 16.10 & 25.96 & 14.67
\end{tabular}

\section{Creative Sector within creative jobs (\%)}

\begin{tabular}{lrrr} 
Advertising & 2.96 & 5.24 & 23.28 \\
\hline Architecture and design & 3.15 & 2.43 & 22.45 \\
\hline Design, designer fashion \& Crafts & 7.43 & 44.64 & 5.15 \\
Film, TV, Radio and Photography & 4.93 & 13.58 & 8.30 \\
Music and Performing Arts & 2.36 & 24.31 & 9.06 \\
Publishing & 1.57 & 4.24 & 11.84 \\
Software, computer games \& & 76.77 & 2.29 & 11.13 \\
Electronic Publishing & & & \\
Libraries, museums \& art galleries & 0.83 & 3.27 & 8.79
\end{tabular}

\begin{tabular}{|c|c|c|c|}
\hline \multicolumn{4}{|c|}{$\begin{array}{l}\text { Type of Creative Job within Creative Jobs } \\
(\%)\end{array}$} \\
\hline Specialist & 32.83 & 47.48 & 32.49 \\
\hline Supportive & 14.04 & 19.47 & 29.22 \\
\hline Embedded & 53.13 & 33.05 & 38.29 \\
\hline
\end{tabular}


Table 3b: DT graduates and CAD graduates in embedded occupations: sectors \& jobs

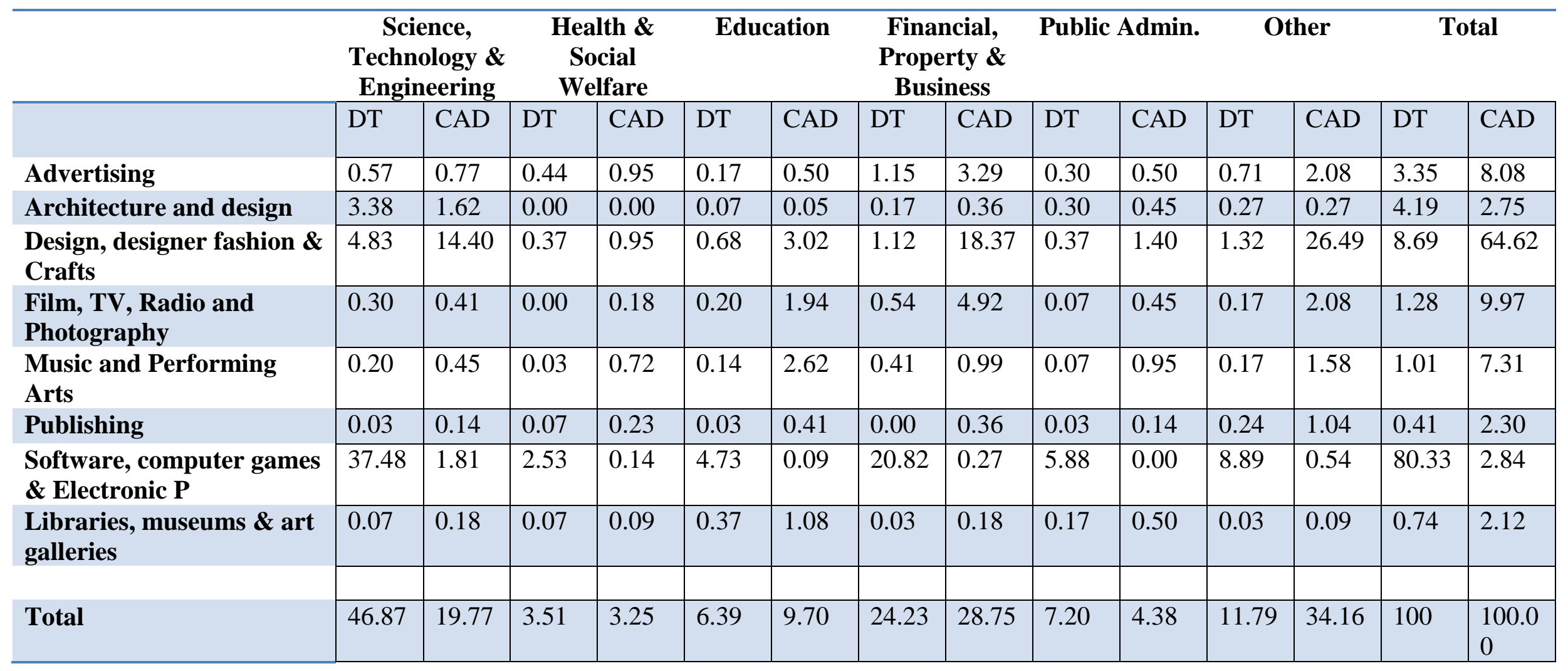


Table 4: Mean Salary (£) by Subject group (undergraduates only)

\begin{tabular}{lrrr}
\hline & All & $\begin{array}{r}\text { Creative } \\
\text { job }\end{array}$ & $\begin{array}{r}\text { Non- } \\
\text { creative } \\
\text { job }\end{array}$ \\
\hline DT & 19,387 & 14,828 & 18,490 \\
CAD & 20,486 & 15,682 & 18,014 \\
Other & 18,520 & 14,313 & 18,548 \\
\hline & & & \\
\hline Total & $\mathbf{1 8 , 2 8 6}$ & $\mathbf{1 8 , 1 4 0}$ & $\mathbf{1 8 , 3 1 3}$ \\
\hline
\end{tabular}


Table 5: Mean Salary by Sector and Creative Sub Sector (undergraduates only)

\begin{tabular}{|c|c|c|c|c|}
\hline Creative sectors & $\begin{array}{l}\text { Mean } \\
\text { Salary } \\
\text { (f) }\end{array}$ & $\begin{array}{l}\text { Mean } \\
\text { Salary (f) } \\
\text { Specialised }\end{array}$ & $\begin{array}{l}\text { Mean } \\
\text { Salary (£) } \\
\text { Supportive }\end{array}$ & $\begin{array}{l}\text { Mean } \\
\text { Salary (f) } \\
\text { Embedded }\end{array}$ \\
\hline Creative sector & 18,141 & 17,557 & 17,284 & 19,032 \\
\hline Advertising & 17,806 & 17,496 & 18,398 & 17,824 \\
\hline Architecture and design & 19,012 & 16,985 & 19,654 & 20,831 \\
\hline Design, designer fashion \& Crafts & 16,183 & 15,760 & 15,796 & 16,554 \\
\hline Film, TV, Radio and Photography & 15,900 & 16,122 & 15,751 & 15,907 \\
\hline Music and Performing Arts & 16,342 & 16,959 & 15,046 & 17,434 \\
\hline Publishing & 16,812 & 16,357 & 17,223 & 16,533 \\
\hline $\begin{array}{l}\text { Software, computer games \& } \\
\text { Electronic } P\end{array}$ & 21,100 & 20,723 & 18,843 & 22,019 \\
\hline Libraries, museums \& art galleries & 14,451 & 14,284 & 14,164 & 14,838 \\
\hline
\end{tabular}


Table 6: Odds Ratio from a Logit of the Likelihood of Getting a Creative Job

\begin{tabular}{|c|c|c|c|c|}
\hline & $\begin{array}{l}\text { All } \\
\text { Subjects }\end{array}$ & $\begin{array}{l}\text { Digital } \\
\text { technology }\end{array}$ & $\begin{array}{l}\text { Creative } \\
\text { Arts }\end{array}$ & Other \\
\hline \multicolumn{5}{|c|}{ Personal Characteristics } \\
\hline Female & $\begin{array}{l}0.632 * * * \\
{[-14.175]}\end{array}$ & $\begin{array}{l}0.647 * * * \\
{[-7.188]}\end{array}$ & $\begin{array}{l}0.627 * * * \\
{[-10.736]}\end{array}$ & $\begin{array}{l}0.701 * * * \\
{[-5.784]}\end{array}$ \\
\hline \multicolumn{5}{|c|}{ Age on graduation (ref: 21 and under) } \\
\hline $22-24$ & $\begin{array}{l}1.083 * * \\
{[2.375]}\end{array}$ & $\begin{array}{l}1.159 * * \\
{[2.022]}\end{array}$ & $\begin{array}{l}1.370 * * * \\
{[4.859]}\end{array}$ & $\begin{array}{l}0.984 \\
{[-0.307]}\end{array}$ \\
\hline $25+$ & $\begin{array}{l}0.757 * * * \\
{[-4.679]}\end{array}$ & $\begin{array}{l}0.937 \\
{[-0.690]}\end{array}$ & $\begin{array}{l}1.508 * * * \\
{[4.652]}\end{array}$ & $\begin{array}{l}0.815 * * \\
{[-2.046]}\end{array}$ \\
\hline Disabled & $\begin{array}{l}1.150 * * * \\
{[4.602]}\end{array}$ & $\begin{array}{l}1.134 \\
{[1.483]}\end{array}$ & $\begin{array}{l}1.155^{* * *} * \\
{[2.587]}\end{array}$ & $\begin{array}{l}1.177 * * * \\
{[2.635]}\end{array}$ \\
\hline \multicolumn{5}{|c|}{ Ethnicity (ref: white) } \\
\hline Black & $\begin{array}{l}0.852 * * \\
{[-2.249]}\end{array}$ & $\begin{array}{l}0.698 * * * \\
{[-3.232]}\end{array}$ & $\begin{array}{l}0.975 \\
{[-0.200]}\end{array}$ & $\begin{array}{l}0.775 * \\
{[-1.769]}\end{array}$ \\
\hline Asian & $\begin{array}{l}0.746 * * * \\
{[-5.687]}\end{array}$ & $\begin{array}{l}0.671 * * * \\
{[-5.467]}\end{array}$ & $\begin{array}{l}1.101 \\
{[0.934]}\end{array}$ & $\begin{array}{l}0.998 \\
{[-0.024]}\end{array}$ \\
\hline Mixed & $\begin{array}{l}1.131 * \\
{[1.650]}\end{array}$ & $\begin{array}{l}1.215 \\
{[0.969]}\end{array}$ & $\begin{array}{l}1.416 * * \\
{[2.304]}\end{array}$ & $\begin{array}{l}0.837 \\
{[-1.063]}\end{array}$ \\
\hline Other & $\begin{array}{l}1.18 \\
{[1.605]}\end{array}$ & $\begin{array}{l}1.009 \\
{[0.048]}\end{array}$ & $\begin{array}{l}1.475^{*} \\
{[1.652]}\end{array}$ & $\begin{array}{l}1.096 \\
{[0.403]}\end{array}$ \\
\hline
\end{tabular}

Subject group (ref: Other

subjects)

Digital Technology $\quad 4.906^{* * * *}$

[29.503]

Creative Arts $5.084 * * *$

[24.555]

Degree classification (ref: Upper second)

$\begin{array}{lllll}\text { First } & 1.312^{* * *} & 1.602^{* * *} & 1.619 * * * & 1.434 * * * \\ & {[8.880]} & {[8.154]} & {[7.935]} & {[5.827]} \\ \text { Lower second } & 0.653^{* * *} & 0.577^{* * *} & 0.636^{* * *} & 0.684 * * * \\ & {[-19.671]} & {[-9.644]} & {[-9.732]} & {[-7.829]} \\ \text { Third/pass } & 0.490^{* * *} & 0.391^{* * *} & 0.466^{* * *} & 0.580^{* * *} \\ & {[-15.008]} & {[-11.206]} & {[-9.157]} & {[-5.462]} \\ \text { Other degree class } & 0.396 * * * & 0.483^{* * *} & 1.057 & 1.859^{* *} \\ & {[-7.126]} & {[-3.957]} & {[0.210]} & {[2.252]} \\ \text { Institution Type (ref: New } & & & & \\ \text { University) } & & & & \\ \text { Russell group } & 1.071 & 1.336^{* * *} & 0.816^{*} & 0.902 \\ & {[0.818]} & {[2.825]} & {[-1.741]} & {[-0.826]} \\ \text { Other old } & 0.985 & 1.290^{* * *} & 1.055 & 0.675 * * *\end{array}$




\begin{tabular}{lllll} 
& {$[-0.207]$} & {$[3.247]$} & {$[0.454]$} & {$[-3.082]$} \\
HE/FE Colleges & 0.933 & 0.79 & 1.131 & $0.704 * *$ \\
& {$[-0.608]$} & {$[-1.336]$} & {$[0.876]$} & {$[-1.986]$} \\
\hline Observations & 138,213 & 10,652 & 15,014 & 28,233 \\
Log likelihood & $-53,600$ & $-6,761$ & $-9,664$ & $-14,209$ \\
LR Chi2 & 3,254 & 748 & 459 & 187 \\
pseudo r-squared & 0.111 & 0.0539 & 0.0317 & 0.02 \\
\hline
\end{tabular}

Robust $\mathrm{t}$ statistics in brackets, standard errors clustered at institution level

$* * * \mathrm{p}<0.01, * * \mathrm{p}<0.05, * \mathrm{p}<0.1$ 
Table 7: Salary Determinants

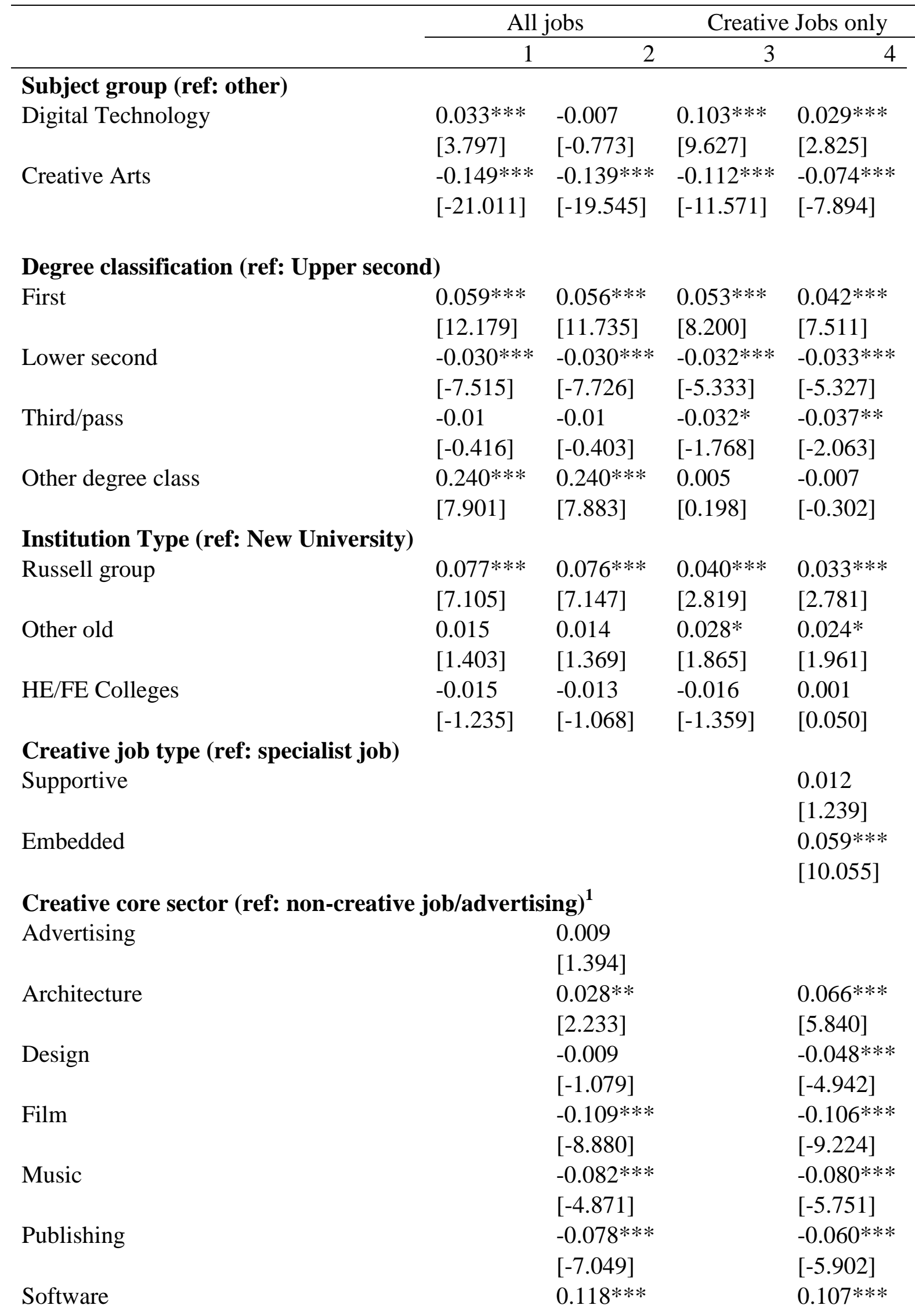


Libraries
[15.112]

[8.785]

$-0.164 * * *$

$-0.166^{* * *}$

[-9.886]

Observations

59,315

59,284

9,239

9,234

pseudo r-squared

0.29

0.299

0.259

0.327

Robust $\mathrm{t}$ statistics in brackets, standard errors clustered at institution level $* * * \mathrm{p}<0.01, * * \mathrm{p}<0.05, * \mathrm{p}<0.1$

1 - with the inclusion of creative job type advertising is the reference group 